\title{
Hidroquímica na Amazônia Central. II. Flutuaçōes no fluxo de saída de nitrogênio e fósforo em dois ecossistemas na Amazônia $\left(^{(*)}\right.$
}

\author{
J. S. Boabaid Ribeiro (**) \\ S. R. B. Bringel (**) \\ A. Santos $\left({ }^{* *}\right)$
}

\section{Resumo}

Foram feitas análises de água de quatro igarapés, dos quais dois drenam uma área de campina na Amazônia Central, o terceiro e o quarto drenando "terra firme de floresta", situados ao longo da rodovia BR-174. O estudo foi feito durante um ano ininterrupto, com a finalidade de conhecer o fluxo de saída de nutrientes essenciais do ecossistema da campina em comparação com a floresta de terra firme. Os dados permitem verificar que existe uma curva para cada igarapé, em um ciclo anual, e que apesar das perdas $\mathrm{N}$ e $\mathrm{P}$ não constituem fatores limitantes para o ecossistema da campina visto que esses elementos são fornecidos pela manta orgânica morta, que é depositada no solo pelos vegetais, e também pela lixiviação de troncos e folhas e ainda pelas chuvas.

\section{INTRODUÇÃO}

Do conhecimento completo do fluxo de nutrientes, depende em parte o controle e manejo de um ecossistema. Um ponto muito válido, no estudo da circulação dos elementos nutritivos, é conhecermos o comportamento do fluxo de saída e sabermos o quanto perde o ecossistema com a saída dos nutrientes estritamente indispensáveis aos produtores primários, dos quais depende toda a biomassa dos outros niveis tróficos.

Assim, este nosso trabalho visou a conhecer o fluxo da saída de nutrientes de um ecossistema de campina, na Amazônia Central, através das águas de igarapés que drenam o sistema ecológico, em comparação com um sistema de terra firme de floresta.

A área da campina em questão está situada entre os quilômetros 60 e 63 da rodovia BR-174 (Fig. 1), e localizada no ponto $60^{\circ} 00^{\prime} 00^{\prime \prime}$
W e $2^{\circ} 30^{\prime} 00^{\prime \prime} \mathrm{S}$ (Santos \& Ribeiro, 1975) e se constitui uma das Reservas Biológicas do INPA. É circundada por três igarapés, dois dos quais formados pela água de percolação, vindas do lençol freático originado das águas de chuva. Sua descrição quanto a vegetação, solo, e fatores climáticos tem sido feita por vários autores (Ribeiro \& Santos), 1975; Lisboa, 1975; Anderson et al., 1975; Macêdo, 1975).

\section{MATERIAL E MÉTodos}

O presente trabalho foi realizado nas águas dos igarapés referidos acima, cujos nomes e localizações são os seguintes: igarapé do Inferno (marco do $\mathrm{km} \mathrm{60}$ ); igarapé do Firmino ( $\mathrm{km}$ 61) vindos da Campina, igarapé do Guaraná $(\mathrm{km} \mathrm{62})$ e igarapé do Tarumazinho situado no $\mathrm{km} 47$ da rodovia BR-174, como representantes de "terra firme de floresta".

Para as determinaçōes de Nitrogênio de Kjeldahl as amostras foram coletadas em frascos de polietileno, com capacidade para 2.000 $\mathrm{ml}$. As coletas de amostras para $\mathrm{N}-\mathrm{NH}_{4}+$ foram realizadas em frascos de polietileno, de $1.000 \mathrm{ml}$ e fixadas no campo com $5 \mathrm{ml}$ de $\mathrm{H}_{2} \mathrm{SO}_{4} 4 \mathrm{~N}$. As amostras para as determinaçōes de $\mathrm{N}-\mathrm{NO}_{2}^{-}$e $\mathrm{N}-\mathrm{NO}_{3}^{-}$eram coletadas em recipientes de polietileno com capacidade para 500 $\mathrm{ml}$ e fixadas no local com $2,5 \mathrm{ml}$ de $\mathrm{CHCl}_{3}$. As amostras para as determinações de fósforo total eram tomadas nas mesmas condições que para Nitrogênio de Kjeldahl. A amostragem era semanal, compreendendo da $1^{\text {a }}$ semana de junho de 1974 à última dita de maio de 1975.

\footnotetext{
(') - Trabalho inteiramente subvencionado pelo Conselho Nacional de Desenvolvimento Científico e Tecnológico $(\mathrm{CNPq})$.

(*) - Instituto Nacional de Pesquisas da Amazônia, Manaus:
} 


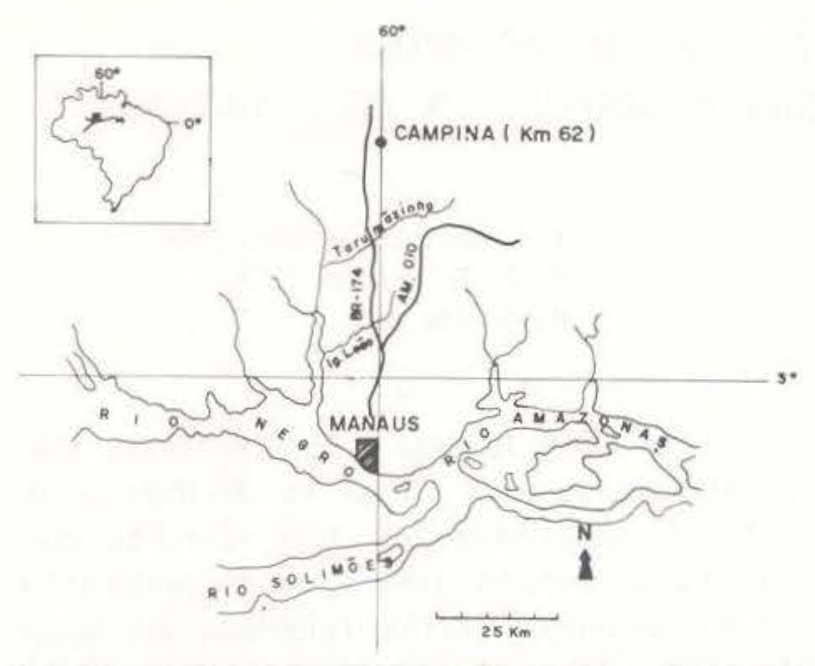

Fig. 1 - Localização da área de campina estudada.

Os métodos empregados, pelos autores, para as determinaçōes consistiram em métodos fotocolorimétricos, assim distribuídos :

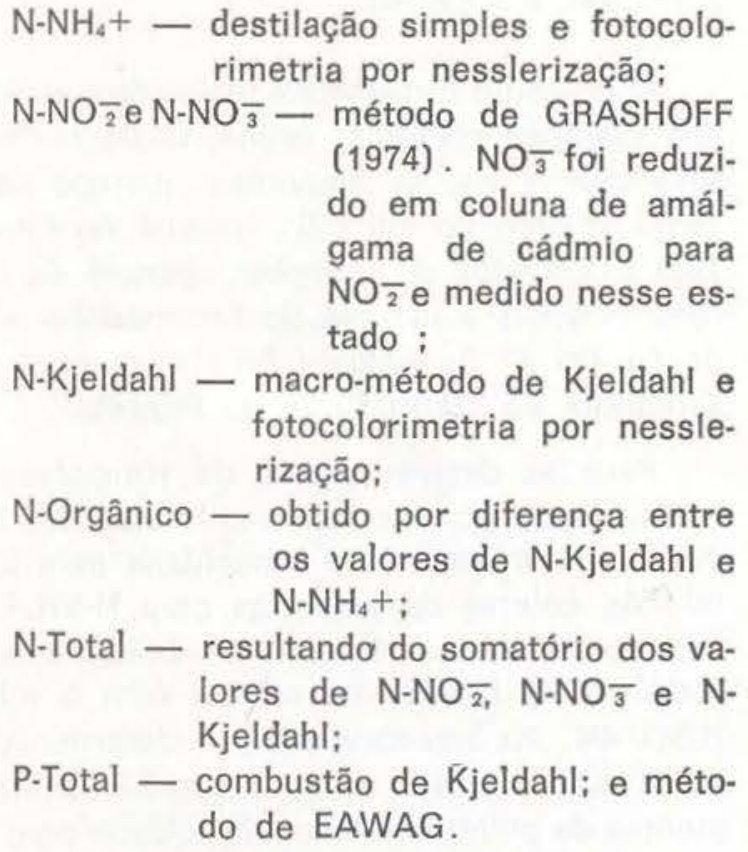

Todas as medições foram efetuadas no fotocolorımetro ELKO II, produzido pela Carl Zeiss. O erro experimental é da ordem de $0,03 \%$.

\section{RESUlTADOS E DISCUSSÃo}

A Fig. 2 e a Tabela 1 apresentam os resultados obtidos de $\mathrm{N}_{-} \mathrm{NH}_{4}+$ nos quatro igarapés, durante o ciclo anual, e permitem ver que os igarapés do Firmino e Inferno recebem, em suas águas, maiores alíquơtas de nitrogênio na forma amoniacal, que os dois outros igarapés. Muito provavelmente, isto é devido a um represamento parcial do líquido naqueles igarapés, o que permite um maior trabalho bacteriológico na produção de amônia, adicionando-se a este fato $\alpha$ arraste desta forma nitrogenada, pelas águas das chuvas, que descem por percolação para a parte sul da campina, enquanto que os dois últimos igarapés, possuindo maior velocidade no deslocamento

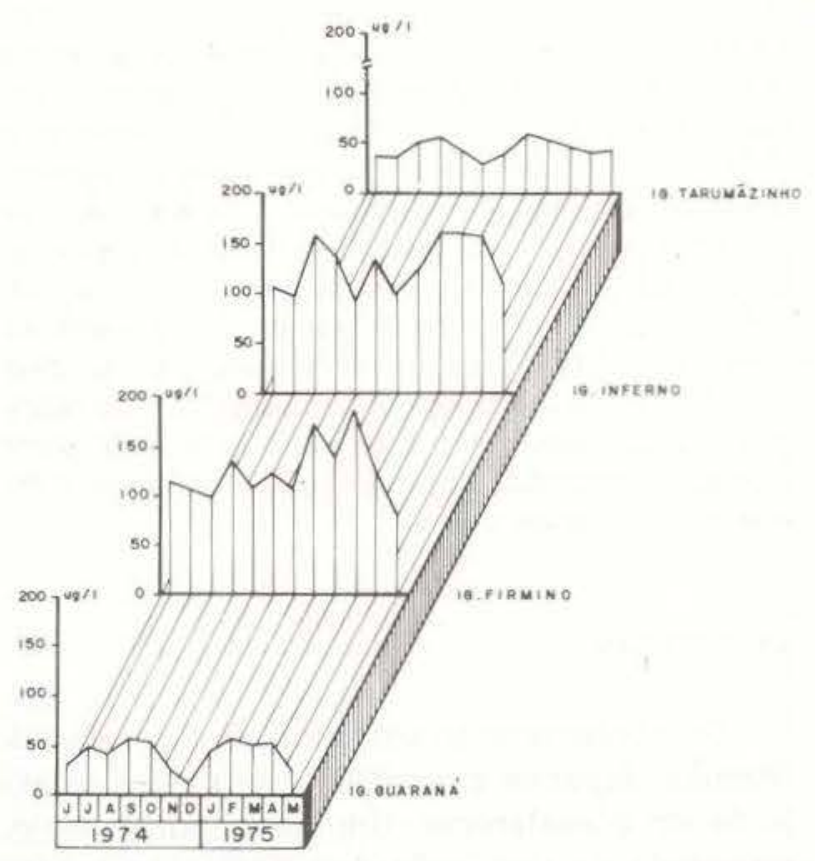

Fig. 2 - Variações mensais de nitrogênio amoniacal

TABELA 1 - Médias mensais de N.NH

\begin{tabular}{lrrrc}
\hline Mês & Guaraná & Firmino & Inferno & $\begin{array}{c}\text { Tarumä- } \\
\text { zinho }\end{array}$ \\
\hline VI.1974 & 30 & 113 & 106 & 36 \\
VII & 50 & 104 & 98 & 35 \\
VIII & 40 & 96 & 158 & 51 \\
IX & 57 & 136 & 137 & 55 \\
X & 54 & 107 & 91 & 44 \\
XI & 26 & 122 & 136 & 28 \\
XII & 11 & 105 & 99 & 36 \\
I.1975 & 42 & 171 & 126 & 50 \\
II & 55 & 133 & 161 & 52 \\
III & 50 & 186 & 161 & 42 \\
IV & 51 & 127 & 157 & 39 \\
V & 26 & 84 & 108 & 40 \\
Média & 41 & 124 & 128 & 42 \\
\hline
\end{tabular}


das águas, não oferece tempo suficiente como nos dois primeiros, para um trabalho mais eficiente das bactérias. Birch (1958) demonstrou que a quebra de compostos orgânicos e inorgânicos de nitrogênio é uma ação puramente bacteriana e a taxa de liberação está diretamente relacionada com o tempo de ação. Os igarapés do Guaraná e do Tarumãzinho apresentaram ciclo semelhante talvez dada a constância de suas velocidades de corrente.

$\mathrm{Na}$ Fig. 3 e na Tabela 2, encontram-se os valores de nitrogênio, em sua primeira subtase de nitrificação, pelo trabalho das bactérias, ou seja, a subfase dos nitritos. Cada igarapé apresentou uma curva diferente e própria, como é claramente notado. Existiu, porém, uma equivalência dos valores de $\mathrm{N}-\mathrm{NO}_{\overline{2}}$, nos quatro córregos, em um mesmo mês (setembro/1974), em torno de $1 \mathrm{ug} / 1$, existindo talvez, nesse período uma equivalência no trabaIho de nitrificação da matéria orgânica, pela microflora, nas águas estudadas.

Os valores encontrados na Fig. 4 e Tabela 3 referem-se a nitratos, última subfase da nitrificação e que constitui a forma em que o nitrogênio é mais rapidamente absorvido pelas

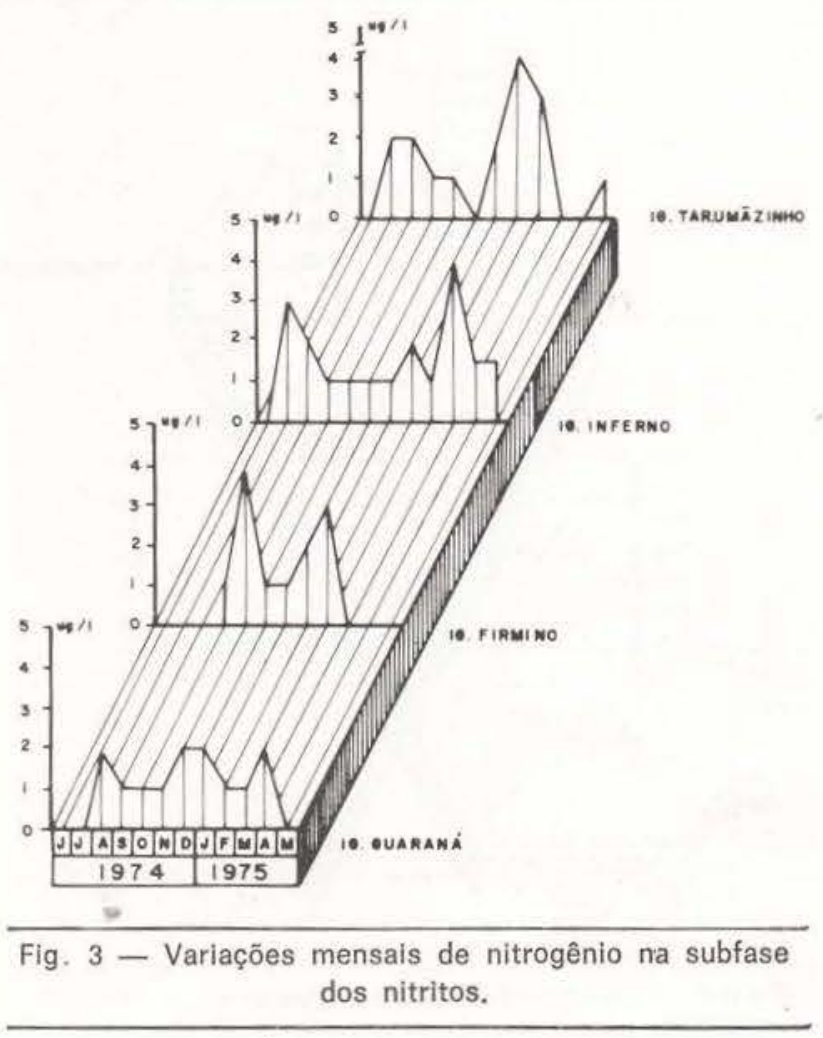

TABELA 2 - Médias mensais de $\mathrm{N}-\mathrm{NO}_{2}$ (ug/ $/$ )

\begin{tabular}{lcccc}
\hline \multicolumn{1}{c}{ Mês } & Guaraná & Firmino & Inferno & $\begin{array}{c}\text { Tarumā. } \\
\text { zinho }\end{array}$ \\
\hline VI.1974 & 0 & 0 & 0 & 0 \\
VII & 0 & 0 & 3 & 2 \\
VIII & 2 & 0 & 2 & 2 \\
IX & 1 & 1 & 1 & 1 \\
X & 1 & 4 & 1 & 1 \\
XI & 1 & 1 & 1 & 0 \\
XII & 2 & 1 & 1 & 2 \\
I. 1975 & 2 & 2 & 2 & 4 \\
II & 1 & 3 & 1 & 3 \\
III & 1 & 0 & 4 & 0 \\
IV & 2 & 0 & 1 & 0 \\
V & 0 & 0 & 1 & 1 \\
Média & 1 & 1 & 1 & 1 \\
\hline
\end{tabular}

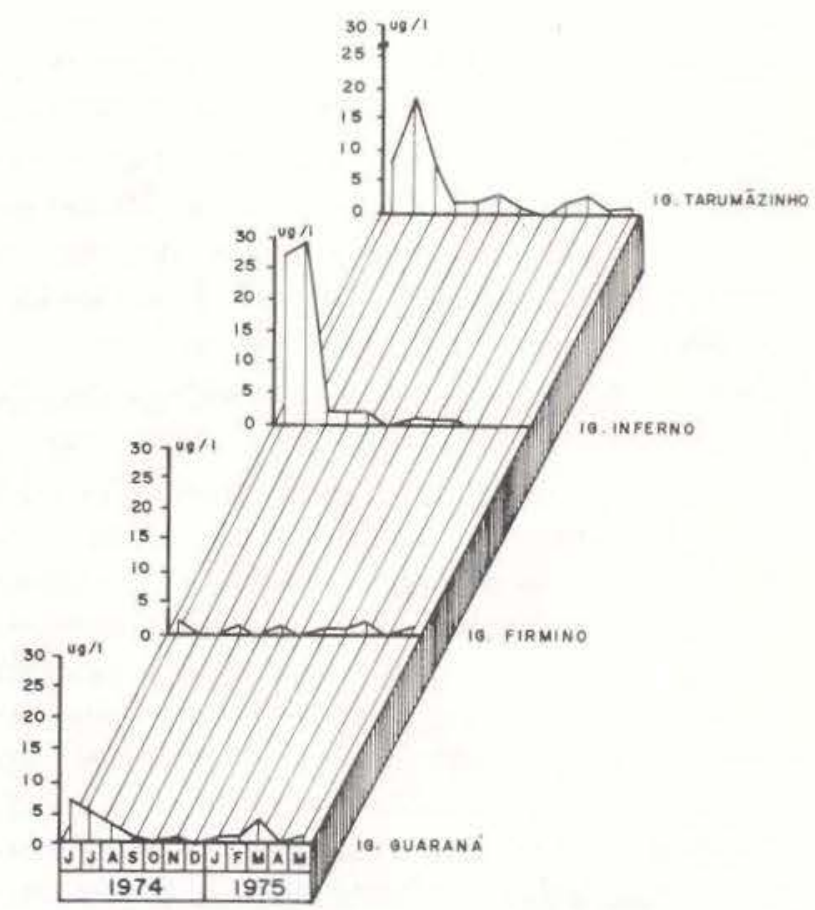

Fig. 4 - Variações mensais de nitrogênio na subfase dos nitratos.

plantas. Aqui, não se verificou a mesma equivalência de valores em um mesmo mês, como ocorreu com os nitritos. Nota-se, entretanto, que os igarapés do Guaraná e do Firmino apresentaram-se como os mais pobres em nitratos, sugerindo que ao serem formados, estes são prontamente absorvidos pela vegetação da campina e poucas são as quantidades que escapam a essa vegetação e assim saem por 
TABELA 3 - Médias mensais de N.NO, (ug/1)

\begin{tabular}{lcccc}
\hline \multicolumn{1}{c}{ Mês } & Guaraná & Firmino & Inferno & $\begin{array}{c}\text { Tarumã- } \\
\text { zinho }\end{array}$ \\
\hline VI. 1974 & 7 & 2 & 27 & 8 \\
VII & 5 & 0 & 29 & 19 \\
VIII & 3 & 0 & 2 & 7 \\
IX & 1 & 1 & 2 & 2 \\
X & 0 & 0 & 2 & 2 \\
XI & 1 & 1 & 0 & 3 \\
XII & 0 & 0 & 1 & 1 \\
I. 1975 & 1 & 1 & 1 & 0 \\
II & 1 & 1 & 1 & 2 \\
III & 4 & 2 & 0 & 3 \\
IV & 0 & 0 & 0 & 1 \\
V & 1 & 1 & 0 & 1 \\
Média & 2 & 1 & 5 & 4 \\
& & & & \\
\hline
\end{tabular}

percolação para esses corpos d'água. Qualquer nutriente nitrogenado formado no solo que não é imediatamente utilizado pela vegetaçầo terrestre está potencialmente disponivel para ser arrastado pelas águas de chuvas (Beadle, 1932; Richardson, 1968 e Carter, 1955) .

O motivo pelo qual os igarapés do Inferno e do Tarumazinho apresentaram as mais altas perdas de nitratos, prende-se talvez a fatores edáficos. Semb \& Robinson (1969) trabalhando com 13 tipos de solos superficiais do Leste da África encontraram um aumento progressivo no conteúdo de nitratos durante a estação seca, com um breve e repentino aumento, no princípio das chuvas, quando a concentração foi severamente reduzida pelo fluxo de saída. Em quase todos os casos, porém, houve muitos outros fatores influenciando o fenômeno. inclusive a quantidade de matéria orgânica, intensidade e duração das estações de seca e de chuva. Griffith \& Manning (1949) verificaram que a maior concentração de nitratos no solo coincidiu com os picos de maior pluviosidade em Uganda.

Conforme pode ser observado na Fig. 4, o pico de $\mathrm{N}-\mathrm{NO}_{3}^{-}$em todos os igarapés, estudados pelos autores, ocorreu nos meses de junho e julho de 1974, após ter havido precipitação máxima, no๊s meses de abril e maio (Fig. 5). deste ciclo. Estes e os dados de Santos \& Ribeiro (1975) sugerem que as águas de preci- pitação que caem na região estudada demoram aproximadamente dois meses para chegar até os igarapés, arrastando consigo o nitrato que escapa à vegetação.

São encontrados os valores de nitrogênio orgânico na Fig. 6 e na Tabela 4. A saída de nitrogênio orgânico, do complexo ecossistema em estudo, foi maior através dos igarapés do Firmino e do Inferno, em cujas águas encontramos seus maiores valores no mês de dezembro/1974, que marca o início da época chuvo-

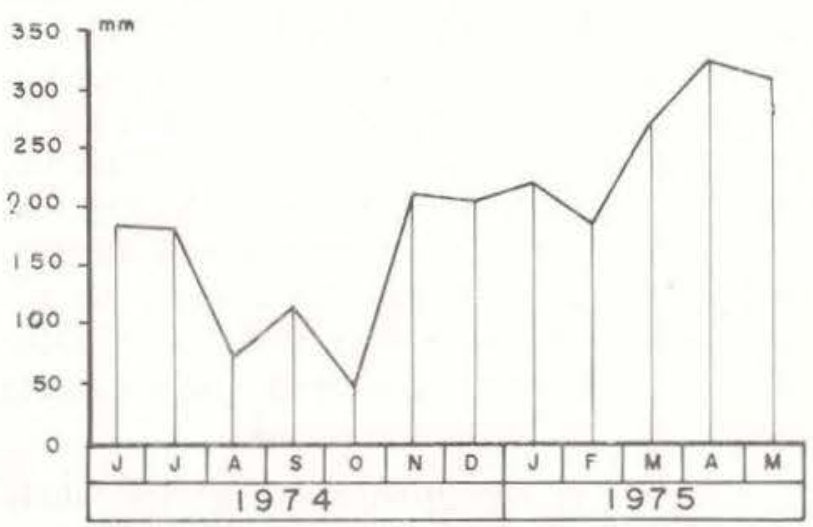

Fig. 5-Dados de precipitação da Reserva Florestal Ducke, (Do Boletim Meteorológico do INPA 1974/1975, por gentileza da Chefe do Setor).

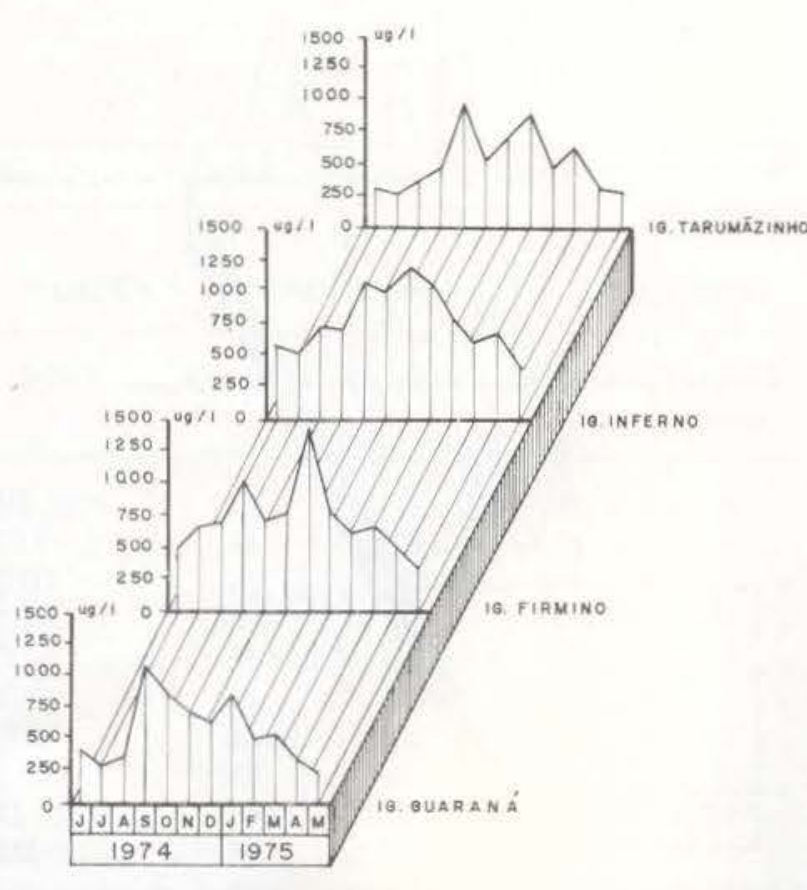

Fig. 6-Variaçōes mensais de nitrogênio orgânico. 
TABELA 4 - Médias mensais de N.Orgânico (ug/)

\begin{tabular}{lrrrc}
\hline \multicolumn{1}{c}{ Mês } & Guaraná & Firmino & Inferno & $\begin{array}{c}\text { Tarumã- } \\
\text { zinho }\end{array}$ \\
\hline VI.1974 & 370 & 367 & 448 & 273 \\
VII & 225 & 393 & 380 & 217 \\
VIII & 470 & 422 & 574 & 319 \\
IX & 1025 & 903 & 577 & 417 \\
X & 804 & 740 & 978 & 933 \\
XI & 704 & 636 & 856 & 488 \\
XII & 612 & 1358 & 1119 & 679 \\
I. J975 & 789 & 616 & 947 & 776 \\
II & 452 & 472 & 668 & 412 \\
III & 483 & 483 & 441 & 579 \\
IV & 316 & 375 & 520 & 287 \\
V & 198 & 248 & 289 & 240 \\
Média & 537 & 585 & 650 & 468 \\
\hline
\end{tabular}

sa. É provável que esta forma de nitrogênio, liberado da matéria orgânica desdobrada pelos decompositores responsáveis por esta fase, durante a época não chuvosa, seja levado em maiores concentrações para estes dois igarapés pelas águas das primeiras chuvas de inverno. O igarapé do Guaraná, recebendo maiores proporções do lençol freático, que se dirige para o lado norte da Campina, concentra mais esta forma de nitrogênio no mês de setembro e é possível que o principal fator con-

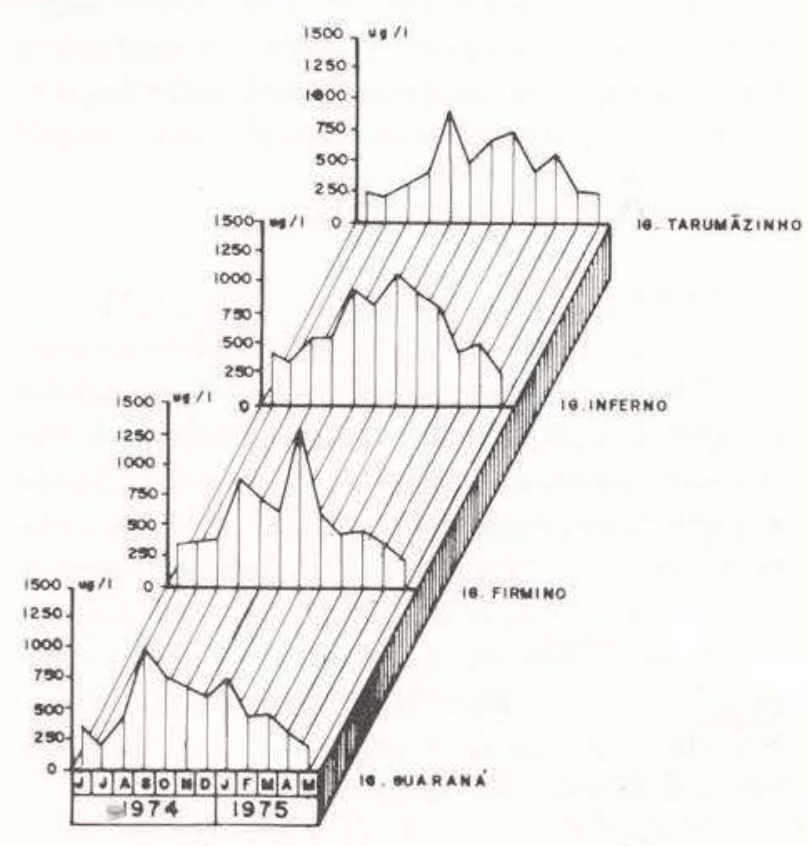

Fig. 7 - Variaçōes mensais de nitrogênio total.
TABELA 5 - Médias mensais de N-Total (ug/1)

\begin{tabular}{lrrrc}
\hline \multicolumn{1}{c}{ Mês } & Guaraná & Firmino & Inferno & $\begin{array}{c}\text { Tarumã- } \\
\text { zinho }\end{array}$ \\
\hline VI. 1974 & 404 & 482 & 576 & 316 \\
VII & 279 & 485 & 508 & 266 \\
VIII & 511 & 518 & 734 & 377 \\
IX & 1082 & 1040 & 715 & 474 \\
X & 860 & 867 & 1072 & 980 \\
XI & 731 & 759 & 993 & 519 \\
XII & 626 & 1465 & 1220 & 718 \\
I. 1975 & 835 & 790 & 1076 & 893 \\
II & 509 & 608 & 831 & 470 \\
III & 538 & 671 & 606 & 624 \\
IV & 357 & 503 & 678 & 316 \\
V & 225 & 333 & 398 & 283 \\
IMédia & 580 & 710 & 783 & 520 \\
\hline
\end{tabular}

trolador ou que governa este fenômeno é o fator edáfico, como também se verifica no igarapé de "terra firme".

Representando o somatório de $\mathrm{N}-\mathrm{NO}_{\overline{2}}$, $\mathrm{N}-\mathrm{NO}_{3}$ e N-Kjeldahl, o nitrogênio total (Fig. 7 e Tabela 5) saido do ecossistema através dos igarapés que o drenam, apresenta valores superiores aos de N-KjeldahI, como é obvio. Confrontando-se os dados aqui obtidos para nitrogênio orgânico e nitrogênio total, com os

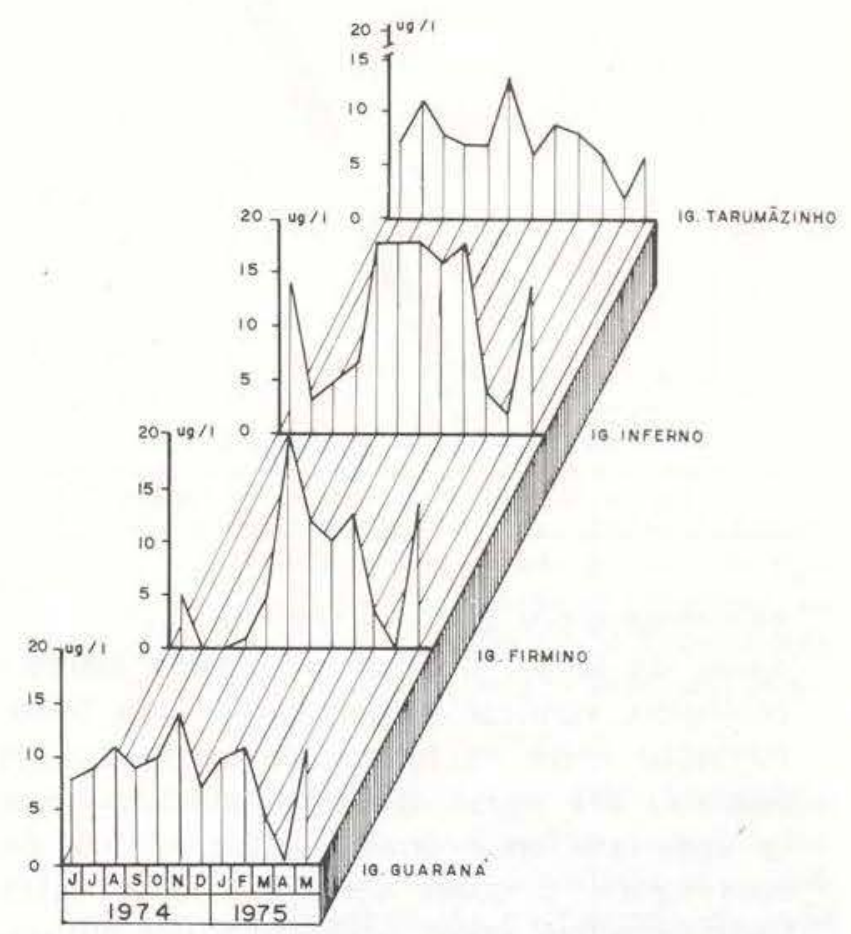

Fig. 8 - Variações mensais de nitrogênio de Kjeldahl. 
TABELA 6 - Médias mensais de N-Kjeldahl (ug/1)

\begin{tabular}{lrrrr}
\hline \multicolumn{1}{c}{ Mês } & Guaraná & Firmino & Inferno & $\begin{array}{r}\text { Tarumã- } \\
\text { zinho }\end{array}$ \\
\hline VI.1974 & 397 & 480 & 549 & 308 \\
VII & 274 & 485 & 476 & 245 \\
VIII & 506 & 518 & 730 & 368 \\
IX & 1080 & 1038 & 712 & 471 \\
X & 859 & 863 & 1069 & 977 \\
XI & 729 & 757 & 992 & 516 \\
XII & 624 & 1464 & 1218 & 715 \\
I. 1975 & 832 & 787 & 1073 & 889 \\
II & 507 & 604 & 829 & 621 \\
III & 533 & 669 & 602 & 465 \\
IV & 355 & 503 & 677 & 315 \\
V & 224 & 332 & 397 & 281 \\
Média & 577 & 708 & 779 & 514 \\
\hline
\end{tabular}

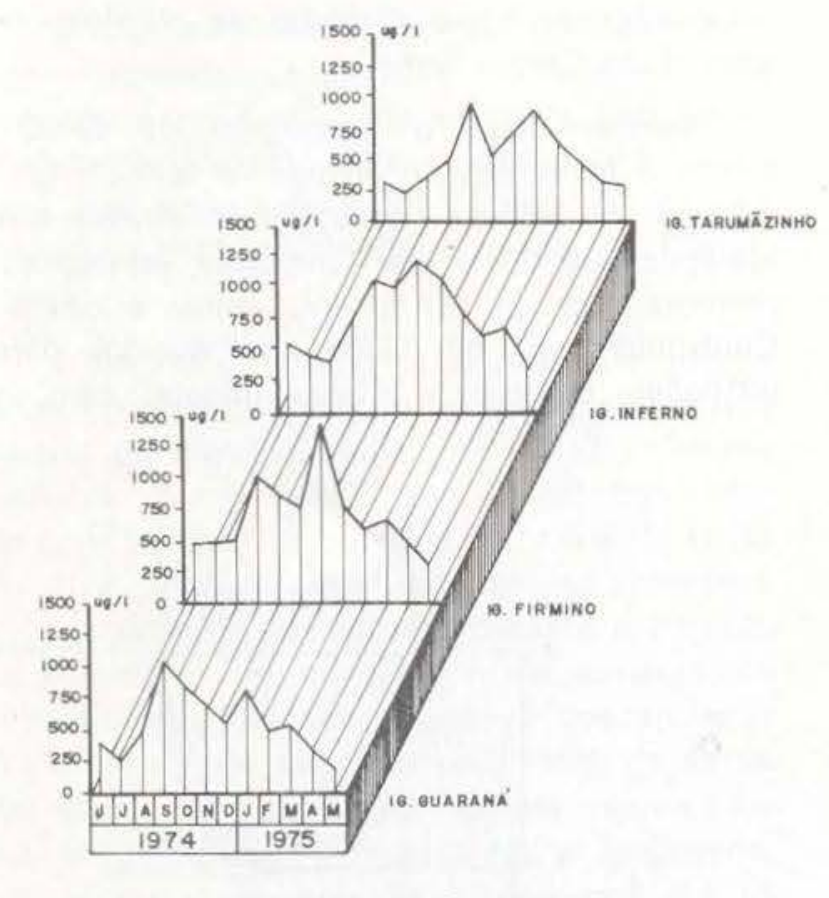

Fig. 9 - Variaçōes mensais de fósforo.

encontrados por Santos \& Ribeiro (1975), nas águas do lençol freático do mesmo sistema ecológico, verificamos que ocorre uma transformação entre as formas de nitrogênio, no percurso das águas até estas chegarem aos igarapés que funcionam como escoadouros de suas águas. É quase certa que todas estas transformaçōes sejam governadas por processos biológicos. Os valores de N-Kjeldahl, são vistos na Fig. 8 e Tabela 6.
TABELA 7 - Médias mensais de P-Total (ug/1)

\begin{tabular}{lrrrr}
\hline \multicolumn{1}{c}{ Mês } & Guaraná & Firmino & Inferno & $\begin{array}{c}\text { Tarumã. } \\
\text { zinho }\end{array}$ \\
\hline VI. 1974 & 8 & 5 & 14 & 7 \\
VII & 9 & 0 & 3 & 11 \\
VIII & 11 & 0 & 5 & 8 \\
IX & 9 & 1 & 7 & 7 \\
X & 10 & 5 & 18 & 7 \\
XI & 14 & 20 & 18 & 13 \\
XII & 7 & 12 & 18 & 8 \\
I.1975 & 10 & 10 & 16 & 9 \\
II & 11 & 13 & 18 & 8 \\
III & 5 & 4 & 4 & 6 \\
IV & 1 & 0 & 2 & 2 \\
V & 11 & 14 & 14 & 6 \\
Média & 8 & 7 & 11 & 8 \\
\hline
\end{tabular}

Gs valores de fósforo obtidos (Fig. 9 e Tabela 7) demonstram que a saida maior deste nutriente, no ciclo estudado, ocorreu no mês de novembro, lımiar entre veräo e inverno, quando as águas concentram maiores quantidades do nutriente em questão. Verifica-se que o igarapé do Inferno apresentou-se como o mais rico em fósforo, cujos valores medianos mensais (18 ug/l) permaneceram em um mesmo nível mais elevado, do $5 .^{\circ}$ ao $9 .^{\circ}$ mês do ciclo, com uma pequena queda de 2 ug/I no $8^{\circ}$ mês. Os outros igarapés apresentaram valores mais baixos, sendo que apenas em um mês (novembro/1974) o igarapé do Firmino superou os demais, sofrendo, logo em seguida uma queda acentuada do seu conteúdo de fósforo.

\section{Conclusão}

Dadas as condições de porosidade do solo da campina, é difícil e quase impossível ocorrer uma lixiviação superficial do solo. Graças a este fator edáfico, o ecossistema se mantém em equilibrio, pois do contrário, em um solo mais compacto, com grandes espaços entre as "ilhas de vegetaçăo", portanto com pouca ou nenhuma cobertura florística, não haveria retenção da manta orgânica da qual se nutre o bioma vegetal.

Diante dos resultados obtidos, verifica-se que em um ciclo sazonal o ecossistema perde, através dos igarapés formados por percolação 
das águas das chuvas, uma considerável quantidade de nitrogênio e fósforo. Entretanto, nem o primeiro nem o segundo parece constituir fator limitante, pois além da espessa manta orgânica morta que oferece tais nutrientes, as águas das chuvas arrastam para o solo grandes concentrações dos mesmos, quer diretamente da atmosfera, quer por lixiviação de troncos e folhas de árvores, conforme os autores têm observado em análises de tais águas e que foi anteriormente verificado por Long et al. (1956a,b), Tukey \& Amling (1958), Tukey \& Mecklenburg (1964) e Tukey (1964) em outros ecossistemas. Um equilibrio entre matéria orgânica morta depositada no solo (litter) e a vegetação, mantém esta desenvolvida ao ponto em que se encontra. Deve haver uma atividade microbiana muito intensa e que exerce um papel muito importante, talvez decisivo no fluxo de nutrientes, porém, até o momento não existem trabalhos elucidativos sobre a microflora desse ecossistema.

Calder (1957 e 1959) enfatiza a importância da fixaçăo microbiana de nitrogênio elementar em solos de Uganda e também mostra como a fixação é máxima quando há uma oscilação de saturação de umidade do solo típico dos trópicos.

A extensão em que nutrientes são carregados dos sistemas terrestres para os aquáticos diz respeito a uma ineficiente reciclagem interna nos sistemas terrestres (Viner, 1975).

\section{AGRADECIMENTOS}

Os autores expressam aqui agradecimentos aos Drs. J. G. Tundisi e H.O.R. Schubart pelas sugestões apresentadas na apreciação do manuscrito. Estendem seus agradecimentos ao Setor de Meteorologia do INPA, na pessoa de M.N.G. Ribeiro, por permitir a publicação dos dados de precipitação.

\section{SUMMARY}

Waters' analyses were done of four "igarapes", on which two of them are dryer a Campina's area in the Central Amazonia, third and fourth drying a "terra firme" of forest located along of the BR-174 Road. The study had been done during a whole year, in order to know the lost on a cycle of essencial nutrients by Campina $\epsilon$ cosystem, in comparison with a "terra firme". The data permited to verify that there is a curve for each "igarape", in a anual cycle, and that although the lost can be considerable, $\mathrm{N}$ and $\mathrm{P}$ are not limitant factors for the Campina ecosystem, because these elements are given by died organic matter (litter), droped on the soil from vegetables.

\section{BIBLIOGRAFIA CITADA}

Anderson, A.B.; Prance, G.T. \& Albuquerque, B.

1975. - A vegetação lenhosa da Reserva Biológica INPA SUFRAMA (Manaus-Caracarai, $\mathrm{km}$ 62). Acta Amazonica, 5(3): 225-246.

BEADLE, L.C. .

1932 - Scientific results of the Cambridge expedition on the East African lakes, 1930-1. The water of some East African lakes in relation to their fauna and flora. J. Linn. Soc. (Zool.), (38):157-211.

BIRCH, H.F.

1958 - The effect of soil drying on humus decomposition and nitrogen availability. Plant Soil, 10(1) : 9-31.

1959 - Further observations on humus decomposition and nitrification. Plant Soil, $9(3): 262-286$.

CALDER, E.A.

1957 - Features of nitrate accumulation in Uganda soil. J. Soil. Sci., 8(1) : 60-62.

1959 - Nitrogen fixation in a Uganda swamp soil. Nature, (184);746.

CARTER, G.S ,

1955 - The Swamp of Uganda. Cambridge, England. W. Heffer \& Sons Ltda., $186 \mathrm{p}$.

GRIFFITH, G.A. \& MANNING, H.L.

1949 - Fertilizer studies in Uganda soils. E. Africa Agr. J., (15) : 87-97.

LISBOA, R.C.L.

1975 - Brioecologia de uma Campina Amazônica. Tese apresentada ao curso de Pós-graduação do Instituto Nacional de Pesquisas da Amazônia e Universidade do Amazonas, para o grau de M.S., Manaus. $56 \mathrm{p}$.

LISBOA, P.L.B.

1975 - Aspectos ecológicos de Glycoxylon inophyllum, (Mat. ex Miq.) Ducke (Sapotaceae). Tese apresentada ao curso de Pós-graduação do Instituto Nacional de Pesquisas da Amazônia e Universidade do Amazonas, para o grau de M.S., Manaus. $74 \mathrm{p}$. 
LONG, W.G.; Sweet, D.V. \& Tukey, H.B.

1956a - Loss of Nutrients from Plant Foliage by Leaching as Indicated by Radioisotopes. Science, 123(3206):1039-1040.

$1956 \mathrm{~b}$ - The loss of nutrients by leaching of the foliage. Mich. Quart. Bull, 38(4):528-532.

MACEDO, M.

1975 - Dispersão de plantas lenhosas de uma Campina Amazônica. Tese apresentada ao curso de Pós-graduação do Instituto Nacional de Pesquisas da Amazônia e Universidade do Amazonas, para o grau de M.S., Manaus. $181 \mathrm{p}$.

RIbeiro, M.N.G. \& SANTos, A. DOS

1975 - Observações microclimáticas no ecossistema Campina Amazônica. Acta Amar zonica, 5(2):183-189.

RICHARDSON, H.L.

1968 - The use of fertilizers. In: The Soil Resources of Tropical Africa, R.P. Moss ed. A symposium of the African Studies Association of the United Kingdon, C.U.P.

Santos, A. Dos \& Ribeiro, M.N.G.

1975 - Nitrogênio na água do solo do ecos- sistema Campina Amazônica. Acta Ama zonica, 5(2):173-182.

SEMB, G. \& RoBINSON, J.B.D.

1969 - The natural nitrogen flush in different arable soils an climates in East Africa. E. Afr. Agr. For. J., (34):350-370.

TUKEY JR., H.B.

1964 - Leaching of Nutrient from Plant Foliage by Rain and Mist. American Rose Annual, 102-111 p.

TUKey JR., H.B. \& MECKLENBurg, R.A.

1964 - Leaching of metabolites grom foliage and subsequent reabsorption and redistribution of the leachete in plants. Am. J. of Bot., 51(7):737 742 .

TUKEY JR., H.B. \& AMLING, H.J.

1958 - Leaching of foliage by rain and dew as an explanation of differences in the nutrient composition of greenhouse and fiel - grown plants. Quart. Bull., $40(4): 876-881$.

VINER, A.B.

1975 - The Supply of Mineral to Tropical
Rivers and Lakes (Uganda). Verh.
Intern. Verein. Limnol., (23):227-261.

(Aceito para publicação em 11-05-78) 